\title{
A institucionalidade dos sistemas sanitários locais nas linhas da fronteira: impactos no acesso aos serviços e ações de saúde
}

Vera Maria Ribeiro Nogueira ${ }^{1}$ Helenara Silveira Fagundes² Josiane Agustini ${ }^{3}$

1 Doutora em Enfermagem. Professora da Universidade Católica de Pelotas e professora colaboradora do Programa de Pós-graduação em Serviço Social da Universidade Federal de Santa Catarina (UFSC).vera.nogueira@pq.cnpq.br

2 Doutora em Serviço Social. Professora da Universidade Federal de Santa Catarina (UFSC) e coordenadora do Programa de Pós-graduação em Serviço Social da UFSC.elenarasf@hotmail.com

3 Mestre pelo Programa de Pós-graduação em Serviço Social da Universidade Federal de Santa Catarina (UFSC).E-mail - josiagustini@yahoo.com.br 


\section{Resumo}

ESTE TEXTO PROCURA CONTRIBUIR PARA ELUCIDAR UMA DAS QUESTÕES CENTRAIS SOBRE OS SISTEMAS DE SAÚDE EM ÁREAS FRONTEIRIÇAS: OUAIS AS NECESSIDADES DA CIDADANIA EM RELAÇÃO À SAÚDE, OUUE PAPEL DESEMPENHA NAS DECISÕES DAS POLÍTICAS DE SAÚDE E OUE MODELOS DE ORGANIZAÇÃO SÃO NECESSÁRIOS?OBSERVA-SE OQUE A OUUESTÃO DA CIDADANIA NAS LINHAS DE FRONTEIRA, OU SEJA, O DIREITO À SAÚDE, INDEPENDENTEMENTE DE NACIONALIDADE, É UM TEMA COM INSERÇÃO CRESCENTE NAS ESFERAS GOVERNAMENTAIS E NÃO GOVERNAMENTAIS. ISSO OCORRE DEVIDO ÀS DEMANDAS DOS ESTRANGEIROS AOS SISTEMAS DE SAÚDE DE OUTROS PAÍSES, O OUE OBRIGA ESTES A UM REDESENHO CONSTANTE. OS GOVERNOS DA ARGENTINA, BRASIL E URUGUAI, RECONHECENDO ESSA SITUAÇÃO, ESTABELECERAM ACORDOS BINACIONAIS PARA REDUZIR OS IMPACTOS DESSE TIPO DE DESIGUALDADE. NO BRASIL, DOIS PROGRAMAS NACIONAIS FORAM IGUALMENTE INSTITUÍDOS PARA MINORAR O PROBLEMA. $O$ OBJETIVO DO ESTUDO REALIZADO FOI IDENTIFICAR COMO E EM OUE MEDIDA AS INOVAÇÕES DECORRENTES DE NORMAS, REGRAS E PACTOS FORAM INCORPORADAS NA ESFERA MUNICIPAL NA LINHA DE FRONTEIRA COM A ARGENTINA E O URUGUAI, CONFERINDO PADRÕES DE INSTITUCIONALIDADE PASSÍVEIS DE GARANTIR OU NÃO O DIREITO À SAÚDE AOS NÃO NACIONAIS.

\section{Abstract}

THIS ARTICLE SOUGHT TO HELP ELUCIDATE ONE OF THE QUESTIONS OF HEALTHCARE IN BORDER REGIONS, THAT IS: WHAT ARE THE NEEDS OF CITIZENSHIP IN RELATION TO HEALTHCARE AND WHAT IS ITS ROLE IN THE DECISIONS ABOUT HEALTHCARE POLICIES OR CARE FOR INDIVIDUALS? WHAT ORGANIZATIONAL MODELS ARE NEEDED? THE PAPER SOUGHT TO RESPOND TO THIS ISSUE IN A BORDER REGION. IT OBSERVES ISSUES OF CITIZENSHIP IN BORDER REGIONS, OR THAT IS, THE RIGHT TO HEALTHCARE REGARDLESS OF NATIONALITY IS A THEME WITH GROWING INSERTION IN GOVERNMENTAL AND NON-GOVERNMENTAL SPHERES. THIS OCCURS DUE TO THE DEMANDS OF FOREIGNERS UPON LOCAL HEALTHCARE SYSTEMS OF A COUNTRY TO WHICH THEY ARE NOT NATIVE, WHICH REQUIRES CONSTANT RE-PLANNING. RECOGNIZING THIS SITUATION, THE GOVERNMENTS OF ARGENTINA, BRAZIL AND URUGUAY HAVE ESTABLISHED BI-NATIONAL AGREEMENTS TO REDUCE THE IMPACTS OF THIS TYPE OF INEQUALITY. IN BRAZIL, TWO PROGRAMS WERE INSTITUTED TO REDUCE THIS INEQUALITY. THE PURPOSE OF THIS STUDY WAS TO IDENTIFY HOW, AND TO WHAT DEGREE, THE INNOVATIONS FROM THESE NORMS, RULES AND AGREEMENTS WERE INCORPORATED IN THE MUNICIPAL SPHERE AT THE BRAZILIAN BORDERS WITH ARGENTINA AND URUGUAY, CONFERRING INSTITUTIONAL STANDARDS THAT MAY OR MAY NOT GUARANTEE THE RIGHT TO HEALTHCARE TO NON-NATIONALS.

\section{PALAVRAS-CHAVE:}

Direito à saúde; Sistemas locais de saúde; Saúde em linhas de fronteiras; Institucionalidade.

Revista Brasileira de Monitoramento e Avaliação | Número 9 | Janeiro-Junho de 2015

A institucionalidade dos sistemas sanitários locais nas linhas da fronteira: impactos no acesso aos serviços e ações de saúde 


\section{Introdução}

O direito à saúde nas regiões de fronteira é um tema com inserção recente nos debates em esferas governamentais e não governamentais e expressa uma variedade de sentidos de acordo com a postura ética e política dos distintos sujeitos coletivos envolvidos com seu alcance, garantia e fruição. Constata-se, compreensivelmente, a centralidade do debate sobre os aspectos políticos inerentes à ampliação e à garantia dos direitos, visto seu impacto direto sobre o ponto nodal das políticas públicas de corte social, ou seja, a universalidade da atenção em diferentes níveis - básica, de média e de alta complexidade. Entretanto, em relação à política nacional de saúde, um aspecto pouco avaliado é o trânsito entre as consignas contidas nas diretrizes do próprio sistema nacional e sua operacionalização pelos gestores em uma área designada como transfronteiriça.

Estudos anteriores demonstram o alto grau de diversidade apresentado pelos sistemas locais em municípios limítrofes com outros países, podendo-se inferir que as orientações constitucionais e legais, jurídicas e administrativas não são seguidas in totum pelos gestores municipais de saúde (GIOVANELLA;GUIMARÃES, 2007). Tal diversidade é influenciada, além dos níveis de cultura política, por uma variedade de fatores, destacando-se as tradições nacionais e regionais, as estruturas políticas, o grau de desenvolvimento econômico, as ideologias, entre outros, os quais impactam diretamente as concepções sobre o direito à saúde e ações práticas relativas à sua efetivação. Em regiões fronteiriças, essa diversidade reverbera não unicamente entre os brasileiros, mas especialmente sobre os estrangeiros residentes, não residentes, naturalizados e turistas, potencializando desigualdades étnicas, além das econômicas, de gênero e de classe.

A revisão de literatura sinaliza para a existência de diferentes compreensões acerca do significado do direito à saúde em fronteiras, ocasionando perfis diferenciados de atenção às demandas por parte dos estrangeiros que vivem nesse espaço geopolítico. Tal constatação parece indicar dois fatores interligados: o primeiro, a inexistência de princípios éticos e políticos comuns, decorrentes da política nacional de saúde; o segundo parece revelar níveis de institucionalidade frágeis, incapazes de absorver a demanda dos usuários não brasileiros protegidos pelo Estatuto do Estrangeiro (NOGUEIRA, 2006)4. Verificou-se também que os acordos e pactos bilaterais firmados entre os governos brasileiro, argentino e uruguaio garantindo o direito da atenção à saúde não têm tido, até o momento, consequências práticas. Em alguns casos, há o completo desconhecimento sobre tais convenções, por parte dos gestores e profissionais.

Particularizando, entre a população estrangeira que acessa o sistema de saúde, observa-se a permanente incerteza quanto ao tipo de atendimento a ser recebido em caso de necessidade. No lado brasileiro, inexistem padrões uniformes de atenção, favorecendo decisões pessoais dos gestores e dos profissionais de saúde e dificultando o planeja- 
mento de ações integradas entre os sistemas de saúde dos municípios brasileiros e de outros países (NOGUEIRA, 2006).

As consequências de tais situações rebatem diretamente nas demandas colocadas aos profissionais nos vários níveis de atenção à saúde. Na maior parte das vezes, esses são acionados tanto pelos usuários como pelos gestores no sentido de encaminhar as solicitações, causando, em inúmeras ocasiões,conflitos éticos devido à incompatibilidade entre os dispositivos legais e a possibilidade de atenção à saúde(SILVA, 2006).

A análise desse quadro exige rever as significativas transformações pelas quais passou o sistema nacional de saúde brasileiro após o retorno ao Estado democrático de direito. A Constituição Federal de 1988 instituiu um novo reordenamento para o setor de saúde, ao propor um desenho particular a aspectos ético-políticos e aos técnicos operativos fundamentais. Universalizou o direito à saúde, acenando para o pleno acesso aos serviços, sem quaisquer critérios de exclusão ou discriminação. De forma positiva, definiu espaços para a gestão democrática dos serviços de saúde, com a possibilidade legal da participação popular, instituindo constitucionalmente o controle social realizado por diferentes sujeitos.
De acordo com Gerschman (2001), o final dos anos 1990 foi marcado por diversos avanços no redesenho das instituições responsáveis pelas políticas de saúde a partir do texto constitucional. As inovações ocorreram, principalmente, no mecanismo de descentralização das políticas públicas, na busca pela reordenação do sistema com centralidade nos princípios do Sistema Único de Saúde (SUS) e no processo de descentralização das ações nas três esferas de governo. Observam-se, assim, mudanças importantes nas formas de gestão e organização do sistema de saúde, remodelando a operacionalização do SUS. Essas alterações institucionais buscavam descentralizar e democratizara gestão e o acesso aos bens, serviços e ações de saúde em todo o país.

Considerando a situação acima, este artigo enfoca os padrões institucionais propostos pela atual Política Nacional de Saúde em uma faixa geopolítica peculiar: a fronteira. O objetivo foi identificar como e em que medida as inovações decorrentes das normas, regras e pactos, relativos ao princípio da descentralização, foram incorporadas na esfera municipal, na região de fronteira com o Mercosul, conferindo padrões de institucionalidade passíveis de garantir ou não o direito à saúde.

4 No presente trabalho, os municípios estudados são os que estão na fronteira com Argentina, Uruguai e Paraguai.

Revista Brasileira de Monitoramento e Avaliação | Número 9 | Janeiro-Junho de 2015 
Destaca-se a concepção de institucionalidade aqui adotada, relativa ao respeito às regras institucionais, democraticamente consensuadas, permitindo continuidades regulatórias nos processos de gestão dos sistemas de saúde e garantindo a efetividade de suas atribuições na transição entre o plano ético-político e o técnico-operativo. Entende-se, também, o processo de institucionalidade como uma das formas de exercício de poder através das políticas sociais e, no caso específico, das políticas de saúde.

Na análise de O’Donnell, as instituições

[...] são padrões regularizados de interação que são conhecidos, praticados e aceitos regularmente [...] por agentes sociais dados e que, em virtude dessas características, esperam continuar interagindo sob regras e normas incorporadas (formal ou informalmente) nesses padrões. Como espaços de interações sociais, geram rotinas de comportamentos previsíveis, corporificando símbolos e papéis. Ao agregarem interesses, organizam as formas de representação, cuja legitimidade se dá na capacidade de garantirem acordos. Seu papel é fundamental na organização de uma agenda pública comum influenciando nos processos decisórios e sua efetividade. (O’DONNELL, 1991, p. 32).

Salienta o autor que as instituições apresentam funções específicas além da satisfação das necessidades humanas e da organização das interações sociais. As instituições produzem relações e posições de poder que podem, contraditoriamente, tanto acabar com possibilidades de ação como contribuir para a criação de oportunidades de liberdade ou, ainda, produzir barreiras para a liberdade. $\mathrm{Se}$, de um lado, a institucionalização implica altos custos por não representar apenas o fim do direito à liberdade, mas também o receio do processo de burocratização e de descontentamentos que poderá ocasionar (O’DONNELL,1991), de outro, permite estabelecer uma nova ordem no plano institucional, através de comportamentos instituintes (CHAUÍ, 2006). A pergunta central a ser feita é:institucionalizar o quê, com que sentido e favorecendo a quem?

Conforme Frey (2000), considerar as instituições unicamente de forma positiva, pelo fato de garantirem a estabilidade de sistemas, é uma concepção que exige cautela e constante revisão. $O$ autor sinaliza que as instituições não servem apenas para a satisfação das necessidades humanas e para a estruturação das interações sociais, mas também para determinar posições de poder.

Com base nesse enfoque teórico,foram avaliadas as possibilidades instituintes do SUS no plano organizativo, expressando a materialidade alcançada pelos sistemas locais de saúde no atendimento aos estrangeiros.

\section{Procedimentos metodológicos}

O estudo se fundamentou nas percepções de atores políticos locais quanto às inovações relacionadas à diretriz da descentralização expressas na forma de organização do siste- 
ma e serviços locais de saúde, na gestão do sistema e seu financiamento. Abordou, ainda, as demandas nos serviços de saúde de localidades de fronteira e as estratégias de cooperação e acordos interfronteiriços transnacionais.

Em relação à construção metodológica, inicialmente foi necessário caracterizar as variáveis contextuais, relacionadas à natureza dos sistemas municipais de saúde em suas dinâmicas funcionais, dando conta de atender às suas funções precípuas e, concomitantemente, modelar a atenção à saúde, definindo, em última análise, os destinatários dessa atenção. Trata-se, portanto, de aspectos correspondentes à organização político-administrativa, ao grau de centralização decisória, aos critérios de cobertura e às modalidades de ofertas de serviços.

Para a construção dos indicadores com vistas à obtenção dos dados empíricos e posterior análise, considerou-se o princípio/diretriz da descentralização do SUS, detalhada na Lei n. ${ }^{\circ}$ 8.080 e na Norma Operacional de Assistência à Saúde (NOAS) 2002, sendo a última o dispositivo reorientador da implementação do SUS em seus variados níveis. Assim, foi possível o desdobramento dos indicadores em três grandes eixos: organização do sistema, gestão do sistema e financiamento.

Em relação ao primeiro eixo foram coletadas informações sobre as seguintes variáveis: 1) formas de incorporação das necessidades de saúde junto à comissão bipartite; 2) pautas de negociação para elaboração de planos de pactuação integrados (PPI/colegiados de gestão); 3) suficiência na atenção básica; 4) ações de vigilância em saúde (sanitária, ambiental e epidemiológica); 5) priorização das demandas; 6) mecanismos de identificação dos estrangeiros que acessam o SUS; 7) coordenação e controle da organização do sistema local de saúde.

Quanto ao segundo eixo, as informações privilegiaram: 1) existência de protocolos e orientações relativos a aspectos administrativos e técnicos; 2) existência de mecanismos de organização da demanda; 3) sistemas de referências e contrarreferências; 4) autorização de procedimentos de alto custo (exames, tratamentos etc.); 5) fornecimento de medicamentos básicos e de alto custo; 6) forma de alimentação do Sistema de Informações Ambulatoriais (SIA); 7) coordenação e controle das ações e dos serviços de saúde do município.

Finalmente, em relação ao terceiro eixo, o financiamento, buscou-se detalhar: 1) priorização das áreas programáticas no campo do financiamento; 2) utilização dos recursos do piso da atenção básica (PAB) fixo; 3) adesão ao PAB variável; 4) indicação de especificidades regionais; 5) indicadores de resultados do sistema - existência/alimentação do sistema; 6) coordenação e controle das ações relacionadas ao financiamento do SLS. 
Os dados empíricos foram as informações constantes nos bancos de dados ${ }^{5}$ dos projetos Fronteira Mercosul - um estudo sobre o direito à saúdé, concluído em 2005 - e Saúde nas Fronteiras - estudo do acesso aos serviços de saúde nas cidades de fronteira com países do Mercosul7, concluído em 2007. Foram sujeitos de estudo os 69secretários municipais de Saúde (SMSs) dos municípios fronteiriços brasileiros da Região Sul (Paraná, Santa Catarina e Rio Grande do Sul), entrevistados nos dois projetos mencionados. Vale ressaltar que o universo da pesquisa foram os municípios localizados na linha de fronteira, os lindeiros, com três países participantes do Mercosul e que fazem parte do Arco Sul: Argentina, Paraguai e Uruguai.

Quando se estudam as regiões fronteiriças, não se pode desconsiderar a extensão da faixa de fronteira brasileira e dos limites internacionais envolvidos. É possível identificar a presença de características geográficas específicas e extremamente distintas entre as regiões de fronteira, assim como situações particulares. Esse fato vem se refletindo no tratamento diferenciado junto aos órgãos estatais, no tipo de relação com os vizinhos e, no campo de avaliação das políticas, em opções metodológicas de abordagem, nos instrumentos de coleta de informações e na seleção dos casos para estudos. Especialmente em relação aos estudos multicêntricos, a situação contextual é relevante, conforme assinala Hatz: "[...] o objeto de investigação é de grande complexidade, a tal ponto que o fenômeno de interesse não se distingue facilmente das condições contextuais, necessitando informações de ambos (HATZ, 1999, p. 344)".
A região estudada contou com diversos tipos de influência, principalmente a cultural,de origem europeia, e, mais recentemente, a socioeconômica, ou seja, a decorrente da implantação do Mercosul, abrangendo o Arco Sul. A partir dessas influências, o Ministério da Integração Nacional (MIN) criou uma denominação de três sub-regiões do Arco Sul: a) o Portal do Paraná, no noroeste paranaense; b) os Vales Coloniais Sulinos, que se subdividem em três partes - o sudoeste do Paraná, o oeste de Santa Catarina e o noroeste do Rio Grande do Sul -; e c) a Mesorregião Metade Sul do Rio Grande do Sul, mais conhecida como Campanha Gaúcha (BRASIL, 2005).

Um conceito utilizado, ao se estudar fenômenos sociais em regiões fronteiriças, é o de "cidadesgêmeas",referindo-se à situação de "municípios lindeiros que apresentam uma conurbação ou semiconurbação com a localidade do país vizinho". Assim,

\section{[...] correspondem ao meio geográfico que melhor caracteriza a zona de fron- teira (inclui as faixas de fronteira bra- sileira e do país estrangeiro) e são os alvos principais prioritários das políti- cas públicas. As simetrias e assimetrias entre as cidadesgêmeas nem sempre decorrem de diferenças no nível de desenvolvimento dos países, e sim de sua própria dinâmica e da função que exercem para os respectivos países (BRASIL, 2005, p.152).}

Os dados obtidos foram sistematizados para análise obedecendo à matriz metodológica utilizada para a coleta de informações. Optou-se igualmente por apresentá-los levando 
em conta a mesma lógica utilizada no processo de análise, ou seja, a organização do sistema e dos serviços, a gestão do sistema e dos serviços e o financiamento do sistema.

A respeito da apresentação dos resultados, uma observação pertinente é que essa separação ocorre unicamente para fins analíticos, sendo a processualidade dos sistemas, em sua dinâmica diária, uma totalidade complexa e contraditória. Por essa razão, igualmente, a exposição pode parecer redundante e repetitiva, mas optou-se por correr esse risco e não perder a riqueza da realidade.

\section{Organização do sistema e dos serviços}

Por organização do Sistema Nacional de Saúde compreende-se o princípio da descentralização político-administrativa com direção única, com ênfase na descentralização dos serviços para os municípios e na organização de forma regionalizada e hierarquizada da rede de serviços de saúde em níveis de complexidade crescente. Nessa perspectiva, cada esfera governamental conta com comando único correspondente: a) no âmbito da União, ao Ministério da Saúde; b) no âmbito estadual e no Distrito Federal, à Secretaria Estadual de Saúde ou instância equivalente; c) no âmbito municipal, à Secretaria Municipal de Saúde.

Em relação a esse eixo, percebeu-se inicialmente que algumas das orientações contidas na Norma Operacional Básica (NOB) 1996 e na Norma Operacional de Assistência à Saúde (NOAS) 2002 não vêm sendo seguidas, principalmente em relação à hierarquização do sistema. Os estados e municípios iniciaram o processo de reorganização de acordo com o plano diretor de regionalização, com a divisão em microrregionais e regionais de saúde. A maioria dos municípios dos três estados informou dificuldades na articulação entre esses níveis, repercutindo negativamente no processo de regionalização, o que, no caso das microrregionais e regionais, resulta no não atendimento das solicitações oriundas dos municípios e na incapacidade de suprir as especificidades para as quais foram criadas. Ou seja, há uma série de demandas não preenchidas em relação às necessidades dos municípios de fronteira devido a esse tipo de organização hierárquica, agravadas pela procura de estrangeiros e reduzida cooperação entre os sistemas assistenciais de saúde do outro lado da fronteira.

5 Constam dos bancos de dados, além de entrevistas com 69 gestores locais de saúde dos municípios de fronteira, inquéritos detalhados abordando a questão da saúde na região.

6 Coordenado pela professora Vera Maria Ribeiro Nogueira, da Universidade Federal de Santa Catarina, concluído em 2005.

7 Coordenado pela professora Ligia Giovanella, da Escola Nacional de Saúde Pública, concluído em 2006.

Revista Brasileira de Monitoramento e Avaliação | Número 9 | Janeiro-Junho de 2015 
Entre os aspectos que mais inquietam os secretários municipais de Saúde (SMSs), destaca-se a inexistência de intercâmbio sistemático de informações entre os países, impossibilitando ações mais eficazes no controle das enfermidades e na atenção à saúde. Assim, alguns municípios passaram a criar estratégias próprias para suprir essa ausência. Entre as iniciativas que têm surtido efeito na região, foram citadas as campanhas de prevenção e a criação de um calendário comum de vacinação. Tais ações preventivas de vigilância sanitária e epidemiológica vêm sendo realizadas integradamente apenas em cidades gêmeas de médio e grande porte dos três estados brasileiros. Isso se deve ao trânsito intenso de pessoas deslocando-se de uma localidade a outra na região. Assim, há um avanço importante em relação às ações de vigilância em saúde (epidemiológica, sanitária e ambiental), com a existência de ações integradas com os países vizinhos, que passaram a se preocupar com a repercussão de algumas doenças, como é o caso da dengue, da raiva, da malária etc. Enfatiza-se que a maioria dessas iniciativas de cooperação, segundo as percepções dos gestores, vem ocorrendo apenas em âmbito municipal, sem acompanhamento ou apoio do Ministério da Saúde brasileiro. Destaca-se a influência da Organização Pan-Americana de Saúde monitorando os países vizinhos em relação aos aspectos acima.

Foi possível confirmar os estudos anteriores, segundo os quais o atendimento à população estrangeira não acontece de maneira uniforme (GIOVANELLA; GUIMARÃES, 2007; NOGUEIRA, 2006; PREUSS, 2007; NOGUEIRA; FAGUNDES; PEREZ, 2011). Entre os critérios para o acesso aos serviços mais mencionados pelos secretários municipais de Saúde está a exigência de documentos comprobatórios de identificação nacional e de residência, sendo essa requisição, na maioria dos casos, seguida com rigor. $\mathrm{O}$ atendimento aos usuários estrangeiros, ou a sua não realização, em alguns municípios, ocorre a partir da compreensão do direito à saúde por parte dos profissionais no momento da solicitação. Ou seja, o procedimento é bastante discricionário, pois depende como o agente comunitário de saúde, os enfermeiros e médicos conceituam direito à saúde e a bens e serviços de saúde. Soma-se a isso a resistência dos gestores quanto aos estrangeiros, fundamentada no critério financeiro e em uma concepção de cidadania passível de ser qualificada como ambivalente,conforme Noya (2004). Para esse autor, a ambivalência sobre as atitudes frente à igualdade é expressa em um sentido, quando referidas ao terreno abstrato ou de princípios e valores, e em outro, quando se trata de ações concretas, no plano da materialidade.

A maioria dos SMSs relatou não possuir mecanismos de registro do atendimento a estrangeiros, dificultando sua contabilização perante o Sistema de Informações Ambulatoriais/ SUS, já que o formulário utilizado não possui campo para a inserção desse tipo de registro, com repercussões sérias no financiamento da saúde. Frente à questão, observa-se a presença isolada de dispositivos curiosos, como a criação de um cartão municipal para organizar e identificar a demanda, ou, contrariamente, incluir todos os usuários como brasileiros, fornecendo o cartão SUS para os estrangeiros e desconsiderando a moradia como critério de acesso. Em Santa Catarina, uma cidade gêmea se destaca pela implantação de um 
cartão SUS municipal, em que cada área de abrangência das equipes de saúde da família terá diferenciação por cores. A finalidade do cartão é organizar a demanda e identificar os usuários, devido à grande procura de serviços por parte da população estrangeira. Nesse caso, o secretário de Saúde explica como será o acesso: "Os que não tiverem esse cartão, nós atenderemos igualmente, mas aí, sim, nós teremos um registro mais confiável, fidedigno, das pessoas que não são do município que são atendidas" (secretário 1). Constata-se, assim, que, perante a falta de posicionamento das demais esferas governamentais, os municípios passam a elaborar estratégias para registrar a solicitação procedente da fronteira, de forma isolada e individual. Os secretários não mencionaram o encaminhamento da discussão das dificuldades da fronteira para outras instâncias do sistema de saúde ou esferas públicas.

No tocante às formas de registro e estimativa do número de atendimentos aos não nacionais em seus municípios, 60\% dos SMSs disseram que, na maioria das vezes, os serviços de saúde do SUS aos estrangeiros são registrados como prestados a brasileiros. Esse fato foi relatado por 31secretários de municípios em que existe essa demanda. Menos da metade dos SMSs (40\%) revelaram possuir uma estimativa do número de atendimentos mensais a estrangeiros em seu município.

Foram também apontadas pelos SMSs as formas particulares e peculiares de registro dos serviços de saúde prestados aos não nacio- nais: a) registros através de prontuário por paciente; b) identificação de origem do paciente; c) tabela feita pela Secretaria de Saúde; d) registro feito somente nos casos de vacinação; e) registros de prontuário com o endereço do comprovante de residência (exigência para o atendimento); f) registro feito no atendimento à população indígena; g) informações registradas através de ficha de atendimento individual manual; h) ficha de atendimento ambulatorial (FA); i) anotações em caderno; j) registros na ficha/cadastro individual do paciente de acordo com sua nacionalidade, mas isso quando o paciente não omite o fato de ser estrangeiro ou residir em outro país, apresentando documentos/comprovantes falsos de residência. Os demais SMSs relataram não existir forma de registro específico para estrangeiros (GIOVANELLA et al., 2007).

Apenas 40\% (21) dos SMSs que atendem a estrangeiros mencionaram ter uma estimativa mensal. Oito SMSs apresentaram uma média de até 10 atendimentos mensais a estrangeiros, como é o caso de um município do Rio Grande do Sul: "É insignificante a porcentagem em relação ao número de atendimentos. Nós não temos a estatística exata de pessoas que recorrem ao nosso serviço. Uma média de cinco, seis atendimentos, não chega a $10 \%$ do atendimento total do município" (entrevistado 1). Sete informaram entre $11 \mathrm{e}$ 100 casos, e seis SMSs calcularam entre 100 e 500 casos atendidos por mês. Somente três municípios informaram os números exatos de registro dos atendimentos a estrangeiros.

Revista Brasileira de Monitoramento e Avaliação | Número 9 | Janeiro-Junho de 2015 
Para a maioria dos secretários, a qualidade da atenção à saúde é fragilizada devido à inexistência de mecanismos de troca de informações entre as cidades de fronteira, principalmente sobre aspectos sanitários e epidemiológicos. Os SMSs afirmam, igualmente, a inexistência de iniciativas por parte do Ministério da Saúde brasileiro no sentido de favorecer o necessário intercâmbio de informações de saúde entre os países.

É possível verificar, por outro lado, o desconhecimento, por grande parte dos SMSs, das iniciativas já existentes nas regiões fronteiriças, como as comissões de saúde da fronteira e os comitês de fronteira, que vêm discutindo diversos temas pertinentes à região. Da mesma forma, nota-se que não foram mencionadas as ações em andamento implementadas pelos comitês de fronteira e, tampouco, as orientações do Subgrupo de Trabalho 11, do Mercosul.

Percebeu-se também, na fala de alguns SMSs, a constante referência ao modelo hospitalocêntrico, relacionada à ampliação do ingresso dos não nacionais. Tal comportamento reflete a não incorporação da centralidade, na Política Nacional de Saúde, da atenção básica;das funções relacionadas ao tipo de gestão que o município está habilitado;e das responsabilidades desempenhadas pela média e alta complexidade no SUS. Isso foi observado nos municípios dos três estados pesquisados.

Quanto às ações de cooperação técnica entre os países, são mencionadas reduzidas iniciativas. Um secretário de uma cidade gêmea do Paraná citou, entre as mais importantes, a educação permanente e a realização de congressos de saúde. Em Santa Catarina, um SMS informou a implantação do laboratório de fronteira, que atenderá ao município e à cidade estrangeira vizinha. Diante da inexistência de acordos ligados à área da saúde, alguns SMSs enfatizaram a necessidade de firmar parcerias mais efetivas entre as localidades de fronteira para tratar de forma conjunta de iniciativas de ações sanitárias.

Observa-se que a maioria dos SMSs manifestou-se favoravelmente ao direito de acesso ao SUS pelos estrangeiros residentes em seus municípios. Simultaneamente, porém, reiteraram a necessidade de estabelecer ações prioritárias e que possam contar com a participação efetiva de ambos os países, especialmente em termos financeiros. Repõe-se, aqui, a cidadania ambivalente, distinta quando referida a valores abstratos, ideais normativos ou materialidade das políticas públicas (NOYA, 2004).

\section{Gestão do sistema e dos serviços: incorporação de novas regras}

Na gestão do sistema e dos serviços, ocorreram as maiores alterações e responsabilidades para os municípios. Nesse item, constatou-se a flexibilidade quanto aos requisitos exigidos pela NOAS $2002^{8}$ para habilitação dos municípios, que não vêm sendo seguidos plenamente. Verificou-se a habilitação de municípios sem condições de atender às especificações contidas na lei. Esse procedimento causa transtornos ainda maiores aos gestores com o incremento da demanda estrangeira. 
Por um lado, ficam um tanto obscuras as responsabilidades municipais frente à organização do sistema local de saúde, assumindo os gestores a posição de "meros executores" das ações e serviços desenvolvidos pelas secretarias municipais de Saúde, não incorporando sua função programática prevista na legislação do SUS. Por outro lado, são reduzidas as iniciativas inovadoras no campo sanitário.

Foi possível perceber que a maioria dos municípios brasileiros localizados na região de fronteira presta algum tipo de serviço a estrangeiros. Diante disso, foram notados alguns transtornos devido à falta de autorização para internação hospitalares (AlH) e de controle epidemiológico, além de gastos com a contratação de profissionais, exames, medicamentos e transporte de pacientes. Observa-se, também, a inexistência de organização do atendimento aos usuários estrangeiros ea falta de mecanismos de controle eficazes frente à demanda.

Na atenção básica, os estrangeiros encontram maior facilidade para consultas médicas, medicamentos e imunizações. Isso se deve à inexistência de critérios intransigentes no atendimento, favorecendo a ocorrência tanto de fraudes de documentos como de registros de procedimentos nem sempre exatos por parte dos responsáveis. A mesma situação não é encontrada nos encaminhamentos para a média e alta complexidade, em razão da rigorosa exigência de documentação (como o cartão SUS, comprovado pelo atestado de residência carimbado pelo agente comunitário de saúde (ACS)). Somente nos casos em que o usuário acessou o sistema através da emergência há possibilidade de referência para outros níveis de hierarquização do sistema, ou quando o município arca com as despesas decorrentes desse nível de atendimento.

Ressalta-se, ainda, que a referência aos demais níveis do sistema tem como fator determinante a compreensão dos profissionais e secretários de Saúde no momento do atendimento. Dessa forma, grande parte dos encaminhamentos a outros níveis de complexidade é feita por meio dos tratamentos fora de domicílio (TFDs), pagos pelos municípios com recursos repassados pela esfera estadual. Os gestores utilizam esse mesmo procedimento, em alguns casos, para encaminhar também os estrangeiros. Todavia, constatou-se não existir nenhuma garantia de continuidade do tratamento a esses pacientes.

A inexistência de protocolos e orientações no atendimento da população estrangeira na atenção básica tem favorecido, de certa maneira, o tratamento igualitário e sem qualquer impedimento na maioria dos casos, causando

8 Por ocasião da coleta de dados empíricos, não estava em vigor a Portaria 399, de 22 de fevereiro de 2006, do Ministério da Saúde, referente ao Pacto pela Saúde.

Revista Brasileira de Monitoramento e Avaliação | Número 9 | Janeiro-Junho de 2015 
transtornos aos usuários brasileiros. Isso vem se refletindo de maneira significativa em filas e listas de espera em alguns municípios, o que tem ocasionado sérias discussões entre usuários brasileiros e estrangeiros que disputam as vagas. Esse fator está dificultando também o planejamento das ações e serviços de saúde, pois os gestores não conseguem atender às metas propostas, visto ser a procura sempre maior que a oferta.

Foi possível notar, entre os SMSs, as constantes referências às "trocas de favores" e "laços de fronteira", na tentativa de justificar o atendimento a estrangeiros. Desse modo, observa-se uma situação contraditória, já que o critério principal, formal, para o acesso aos serviços de saúde é o cartão SUS. No entanto, devido à relação de laços de fronteira, abrem-se precedentes para estrangeiros acessarem os serviços sem qualquer exigência. Tal fato sinaliza a existência de relações informais que conduzem a comportamentos potencialmente discricionários pelos atores envolvidos na política de saúde. Os mecanismos não oficiais atuando simultaneamente à legislação, na maioria das vezes, chegam a ser considerados mais importantes que as regulamentações já estabelecidas. Além disso, percebem-se, com frequência, as diferenças ou disputas políticas entre profissionais, secretários e prefeitos nas regiões de fronteira, dificultando o planejamento das ações e serviços de saúde de maneira efetiva.

Curiosamente, não há referência explícita aos acordos bilaterais entre os países, o que favoreceria estabelecer normativas protocolares para ingresso dos não nacionais ao sistema local de saúde.
Há fortes evidências, nos relatos dos SMSs, da não continuidade do tratamento quando os usuários estrangeiros retornam ao país de origem. Com isso, os profissionais não conseguem realizar o acompanhamento adequado aos pacientes, que, na maioria das vezes, retornam à unidade de saúde com o mesmo problema ou com o quadro mórbido agravado. Sobre a questão, um SMS do Paraná informa a ausência de controle, referência e acompanhamento a estrangeiros, tanto de um lado como de outro da fronteira: "O principal problema é que não há um prontuário com a história pregressa do usuário ao qual a equipe possa recorrer, o que dificulta o atendimento" (entrevistado 1). Essa situação expõe as consequências relacionadas à inexistência de protocolos de atenção, ocorrendo dificuldade na troca de informações entre profissionais, o que leva à precarização no atendimento.

Essa questão expressa a insuficiência de mecanismos no Ministério da Saúde (MS), responsável pela articulação internacional, para criar dispositivos que facilitem o acesso a informações e o encaminhamento de pacientes entre os dois países. Tal fator tem se revelado um entrave aos municípios, uma vez que não existem, de forma sistemática, orientações e iniciativas coletivas, fazendo com que cada um desenvolva ações de maneira isolada e distinta para atender às novas exigências.

Assim, em relação aos protocolos e orientações para o atendimento a estrangeiros, é possível identificar duas situações. Constata-se, em alguns municípios, a presença de mecanismos que orientam a demanda assistencial em saúde por parte dos estrangeiros, 
construídos à revelia do MS e por iniciativa de gestores dos municípios fronteiriços. Em outros, há a exigência rigorosa de documentação", tanto para usuários brasileiros como para estrangeiros, para que o serviço seja ofertado. Como cita o SMS de uma cidade gêmea do Rio Grande do Sul, "[...] só em caso de emergência. Até porque tudo é só com o cartão SUS agora. A farmácia, por exemplo, não fornece $o$ atendimento se a pessoa não tem o cartão SUS" (entrevistado 2). Esses critérios vêm sendo cada vez mais utilizados como estratégias para controlar o acesso aos serviços de saúde por estrangeiros em alguns municípios da Região Sul.

Devido à inexistência, já reiterada anteriormente, de protocolos e orientações claros, os SMSs, quando consultados a respeito pelos profissionais, ficam com a responsabilidade de permitir ou não o atendimento. Ou seja, as situações são comunicadas às secretarias municipais, que tomam a decisão, sendo que, nesses casos, os municípios são obrigados a pagar pelos procedimentos.

\section{Financiamento do sistema}

No campo do financiamento, foram observadas inovações estratégicas para a política de saúde, especialmente com a criação de mecanismos de repasse financeiro, de forma direta e automática, para estados e municípios.
Isso favorece o planejamento, a execução e o controle mais efetivo das ações em saúde, sendo estabelecidos tetos financeiros de investimentos em saúde para cada esfera de governo, previstos na programação pactuada integrada (PPI) e nos planos municipais de saúde. Por outro lado, tais mecanismos dificultam a inserção e o atendimento dos usuários estrangeiros, especialmente nos níveis de média e alta complexidade.

A localização de alguns municípios favorece a procura por serviços no lado brasileiro, seja pela gratuidade,seja pela qualidade, fazendo aumentar os gastos no campo da saúde. Frequentemente ocorrem internações, uso de medicamentos, exames, transporte, entre outros procedimentos, para atender à população estrangeira, sendo que os custos são cobertos pela esfera municipal. Destaca-se a prevalência da concepção reducionista de saúde, favorecendo o modelo médico-centrado, com a intensificação das internações e exames de média e alta complexidade.

A situação financeira do sistema local se agrava por ser o contingente populacional de cada município um dos critérios de repasse financeiro do SUS. A população estrangeira e os brasileiros residentes no país vizinho, usuários do sistema de saúde brasileiro, não são contabilizados para a base de cálculo dos repasses do Ministério da Saúde. 
De acordo com a NOAS 2002, algumas áreas têm destinação orçamentária definida, como a equipe saúde da família (ESF) e o Programa de Agentes Comunitários de Saúde, mantidos nos municípios. Porém, segundo os SMSs, esse dispositivo não vem sendo cumprido, principalmente em relação à contrapartida das esferas estadual e federal para os municípios. Com isso, a oferta e a qualidade dos serviços prestados são fortemente prejudicadas, ferindo os preceitos legais já estabelecidos. Além disso, a maioria dos SMSs mencionou a falta de revisão e atualização dos valores contidos na tabela de procedimentos pagos pelo SUS, que, em sua percepção, está defasada.

Um fator de extrema importância para o repasse dos recursos está relacionado à alimentação do sistema SIA/SUS. Há a exigência aos municípios do envio mensal dos indicadores de saúde para que os recursos sejam repassados. Diante de tal exigência, desponta a principal dificuldade dos municípios localizados em regiões de fronteira: como inserir os estrangeiros, sem documentação, no banco de dados? Essa dificuldade deriva do fato de a população estrangeira, não naturalizada ou não residente, não ser contabilizada nos dados demográficos municipais. Dessa forma, os municípios passam a arcar com o total das despesas provenientes desses atendimentos.

Alguns aspectos aparecem com maior frequência na fala dos SMSs. Entre os mais citados estão a priorização de áreas programáticas no campo do financiamento; a utilização dos recursos do PAB fixo e do PAB variável; e a indicação de especificidades regionais. Os aspectos citados com pouca frequência por parte dos SMSs foram os indicadores de resultados do sistema - existência/alimentação do sistema - e a coordenação e controle das ações relacionadas ao financiamento do sistema local de saúde. Apenas um SMS desse segmento de fronteira informou a existência de iniciativas de cooperação financeira entre as cidades, ainda que isso ocorra lentamente. A fala de um dos entrevistados reflete:

[...] o que nós observamos realmente em termos disso é que as coisas estão muito no início, muito primárias, entende, porque isso envolve o Ministério das Relações Exteriores. Então, é um trabalho que tem sido feito entre o Ministério da Saúde do Uruguai e o Ministério da Saúde do Brasil e a parte do Ministério das Relações Exteriores, representado aqui pelo Consulado do Brasil e o Consulado do Uruguai. Essas reuniões estão ainda muito primárias, [...] esse trabalho eu acho que tem que se intensificar muito, porque temos que chegar a um denominador comum. (entrevistado 3).

Um dos relatos assinala a existência do acordo entre Brasil e Uruguai para o atendimento nos sistemas de saúde dos dois lados da fronteira. Como informa um SMS do Rio Grande do Sul: "Porque o que diz a legislação, o que houve nessa relação entre Uruguai e Brasil foi que todas as cidades fronteiriças de $30 \mathrm{~km}$, varia tanto de um lado como de outro, mas o que nós observamos é que só nós que estamos dando, e o Uruguai não dá nada" (entrevistado 4). Também é possível verificar, nessa afirmação, o impacto financeiro ou a troca de 
serviços como um dos óbices de uma possível articulação/harmonização entre os sistemas.

Na fronteira do Paraná com o Paraguai, destacam-se as ações desenvolvidas pela empresa pública Itaipu Binacional, com a criação de um grupo de trabalho de saúde (GT) em 2003. Essa iniciativa procurou formular ações e estratégias visando garantir o atendimento das necessidades de saúde da população fronteiriça, especificamente de Foz do Iguaçu e Ciudad del Este. Nota-se que a atividade do Grupo de Trabalho Itaipu/Saúde no sentido da cooperação entre as autoridades sanitárias brasileiras e paraguaias para o desenvolvimento de ações na região tem sido produtiva no debate sobre a criação de um modelo de integração dos serviços de saúde para regiões de fronteira. Entretanto, tais experiências não foram incorporadas ao sistema local de saúde, ficando a cargo da Usina Hidrelétrica de Itaipu (UHI) o financiamento das ações empreendidas ${ }^{10}$ (SILVA, 2006).

Sabendo-se que as regulações nacionais e normas do SUS não aceitam a realização de qualquer procedimento e consequente pagamento fora do território nacional, um SMS relata as estratégias utilizadas para contornar esse fato. Os procedimentos são inseridos no SIA/SUS, normalmente, como sendo realizados no Brasil.
Bom, legalmente, eu devo pegar a nota de outro, do hospital [referindo-se ao hospital brasileiro], para poder comprovar que eu fiz um pagamento para estrangeiro. Eu não posso pegar a nota lá e empenhar aqui. O tribunal me pega. Eu pego, por exemplo, a nota fiscal de uma farmácia como se tivesse feito uma medicação aqui, e daí repasso aquilo como se fosse compra de medicação.(entrevistado 5).

O SMS fala ainda a respeito das estratégias para informar ao SIA/SUS sobre a realização de outros exames feitos na cidade estrangeira: "Informo, sim. Eu tenho ecografia em $X$ e $Y$ [referindo-se a dois municípios brasileiros]. Então, digamos, conforme a neurose dos médicos daqui para levantar os preços, a gente faz lá na Argentina, porque paga mais barato" (entrevistado 6). Mas ressalta que não é informado que o exame foi feito na cidade estrangeira: "Não, que foi feito na Argentina, não. Mas que foi feito, sim [...] Aqui, na cidade, porque eu tenho o serviço aqui também [referindo-se a um serviço privado]. Às vezes é uma questão de preço" (entrevistado 6).

Os gestores dos municípios localizados em regiões de fronteira vêm buscando, junto às secretarias estaduais de Saúde e ao Ministério da Saúde, alternativas para atender a essas especificidades regionais. Entre as inicia-

10 Entre as ações desenvolvidas mediante articulação do GTItaipu/Saúde, destacam-se o Centro de Diagnóstico DST/AIDS, implantado em Ciudad del Este, o centro de atendimento a gestantes brasiguaias e paraguaias, implementado em setembro de 2006, em Foz do Iguaçu, campanhas de vacinação contra a raiva e febre amarela e outras ações de imunização (SILVA, 2006).

Revista Brasileira de Monitoramento e Avaliação | Número 9 | Janeiro-Junho de 2015 
tivas já firmadas, cita-se a criação do Sistema Integrado de Saúde Fronteiras e o Pacto pela Saúde, respectivamente programas e pactuações que procuram contemplar as regiões fronteiriças com instâncias de discussão e com aportes financeiros para atender às demandas específicas dessas regiões.

\section{Considerações finais}

Retomando as análises realizadas, e recordando ser o objetivo do texto identificar em que medida os padrões institucionais (normas, regras e pactos) relativos ao princípio da descentralização, contido na Política Nacional de Saúde, vêm sendo incorporados na esfera municipal da região de fronteira com países do Mercosul, alguns itens merecem destaque.

Quanto às regras, normas e pactos da política de saúde que materializam a proposta do SUS, pode-se afirmar que a construção da Política Nacional de Saúde e a adesão aos novos padrões institucionais nas regiões de fronteira ocorreram de maneira gradual, propiciando mudanças importantes, com a descentralização, principalmente, na esfera municipal. Esse fato viabilizou aos municípios uma maior participação nos processos de planejamento, execução e avaliação das ações e serviços desenvolvidos, embora alguns SMSs posicionem-se como coadjuvantes e executores de decisões de outros níveis hierárquicos.

Quanto à organização do sistema, algumas das orientações contidas na NOB 1996 e na NOAS 2002 não vêm sendo seguidas, e a maioria dos municípios dos três estados in- formou dificuldades na articulação entre os níveis de hierarquização. Essa dificuldade pode estar relacionada à reduzida preocupação dos atores políticos construtores das novas regras com a situação dos municípios localizados nas áreas das extensas fronteiras brasileiras. A não inclusão de dispositivos facilitadores de cooperação entre os sistemas expressa uma visão reducionista de fronteira, oriunda da antiga doutrina da segurança nacional, supostamente ameaçada pela presença do estrangeiro.

Atualmente, com os processos de integração regional, alteraram-se as percepções, ainda que em decorrência de razões e justificativas eminentemente econômicas, mas tendencialmente expandidas para a dimensão social. Em áreas de fronteira dinâmicas, essa nova posição favoreceu os fluxos populacionais em busca do melhor atendimento, em termos de qualidade, facilidade de acesso e gratuidade. Essa demanda, agora reconhecida, impulsiona iniciativas como a instituição do Programa SIS Fronteiras e a inclusão no Pacto pela Saúde, favorecedores, em tese, de um tratamento distinto aos municípios lindeiros. As iniciativas mencionadas vêm responder a um dos aspectos que mais preocupam os SMSs: a inexistência de troca de informações entre os países, impossibilitando ações mais eficazes no controle das doenças e na atenção à saúde na linha da fronteira.

Verifica-se grande diversidade entre os municípios no atendimento das solicitações dos usuários, brasileiros e estrangeiros, remetendo a níveis de incorporação de instituciona- 
lidade bastante diversos entre si. Em alguns aspectos, há relação e proximidade entre eles, mas, na maioria dos casos, cada município elabora individualmente a estratégia que considera mais adequada para sua situação particular. Portanto, o atendimento ou não aos usuários estrangeiros acontece a partir da compreensão dos profissionais acerca do direito à saúde no momento da procura, sejam esses o agente comunitário de saúde, os enfermeiros, os médicos ou os auxiliares de enfermagem. Em raríssimos casos, inclui-se o staff administrativo. Essa situação, aliada à falta de acompanhamento do paciente ao retornar ao país de origem e à insuficiência de ações preventivas nos países vizinhos, tem como consequência o retorno dos pacientes estrangeiros às unidades de saúde brasileiras com os quadros mórbidos agravados, devido à inexistência de continuidade no tratamento no país de origem.

A diversidade de entendimento e de encaminhamento por parte dos secretários municipais frente à demanda estrangeira pode ser explicada pela inexistência de protocolos e orientações precisos, ocasionando uma incorporação caso a caso e inviabilizando a criação de rotinas administrativas mais consolidadas e permanentes ou iniciativas de articulação entre os países.

Um número expressivo dos gestores em municípios de pequeno porte não incorporou a função programática, como prevê a legislação do SUS, situação que se explicita na falta de clareza quanto às responsabilidades municipais frente à organização do sistema local de saúde. Além disso, a esfera municipal parece esperar que uma entidade externa venha resolver os problemas, quando, na verdade, é corresponsável pela organização. Verifica-se que, mesmo diante das orientações da política nacional, precisas em relação às responsabilidades, estas não estão sendo seguidas, de forma sistemática, pela esfera municipal.

A inexistência de critérios efetivos para o atendimento ao estrangeiro tem se refletido na diversidade de interpretações a respeito do direito ao acesso aos serviços de saúde ofertados pelo SUS. O mais preocupante é a atribuição aos profissionais de saúde da seletividade do sistema em relação aos não nacionais. Considerando a diversidade cultural e ideológica, tanto entre as diversas fronteiras como entre os grupos profissionais, assiste-se a constantes alterações nos critérios e até mesmo a desavenças entre os profissionais e gestores, pois lhes são exigidos constantemente posicionamentos éticos que acabam sendo decididos caso a caso e dependendo da gravidade da situação.

As exigências derivadas da implantação do cartão SUS trouxeram um complicador para os gestores, expresso de duas formas. Os que entendem ser $\mathrm{o}$ atendimento aos estrangeiros um direito pautado na preservação da vida e, portanto, os atendem independentemente

Revista Brasileira de Monitoramento e Avaliação | Número 9 | Janeiro-Junho de 2015 
de qualquer seleção - viram-se impedidos de continuar com essa prática ou, então, passaram a utilizar estratégias distanciadas da legalidade concernente ao setor público, como os subterfúgios de omissão da nacionalidade e outras artimanhas. Por sua vez, os gestores que consideram o direito à saúde restrito aos nacionais intensificaram os mecanismos de controle, impelindo os estrangeiros a usarem também subterfúgios igualmente ilegais, como fraudes de documentos e endereços falsificados. As duas situações não se encaminham para soluções mais equitativas, éticas e politicamente negociadas e não favorecem mecanismos de cooperação transfronteiriça efetivos e duradouros.

As constantes referências dos gestores a "troca de favores" e "laços de fronteira", na tentativa de justificar o atendimento a estrangeiros, podem ser decorrentes de práticas historicamente consagradas por um viés patrimonialista ou, contraditoriamente, ser o reconhecimento tácito do não limite fronteiriço, ou seja, de uma grande região sanitária, na oportuna expressão de um dos entrevistados. Observa-se, nesse quadro, uma situação conflituosa, já que o critério principal para o acesso aos serviços de saúde é o cartão SUS. Entretanto, devido aos laços de fronteira, abrem-se precedentes para estrangeiros acessarem os serviços sem qualquer restrição. Tal fato pode ainda sinalizar a existência de relações informais, conduzindo a comportamentos potencialmente discricionários pelos atores envolvidos na política de saúde. Existem mecanismos informais atuando simultaneamente à legislação já existente e que, na maioria das vezes, chegam a ser considerados mais importantes que as regulamentações consensuadas. Ademais, expressam as diferenças ou disputas políticas entre profissionais, secretários e prefeitos nas regiões de fronteira, dificultando o planejamento das ações e serviços de saúde de maneira efetiva. 
Quanto ao financiamento do SUS, a localização dos municípios favorece a procura por serviços no lado brasileiro, ampliando os gastos no campo da saúde. Isso se deve à frequente utilização de insumos para internações, medicamentos, exames, transporte, entre outros procedimentos, para atender à população estrangeira, financiados pela esfera municipal. Como os demandantes não nacionais, usualmente, não são incluídos como usuários do sistema SIA/SUS, não são contabilizados para a base de cálculo dos repasses financeiros do Fundo Nacional da Saúde ao fundo municipal. Identifica-se uma preocupação frequente dos SMSs em estabelecer mecanismos de cooperação financeira entre os países para atender a essa demanda.

Os municípios localizados em regiões de fronteira vêm buscando, junto às secretarias estaduais de Saúde e ao Ministério da Saú- de, alternativas para atender a essas especificidades regionais. Entre as iniciativas já firmadas, cita-se a criação do SIS Fronteiras e o Pacto pela Saúde, contemplando as regiões fronteiriças com instâncias de discussão e aportes financeiros.

Conclui-se que, mesmo diante das iniciativas de cooperação e integração, a área social não foi contemplada de forma efetiva na construção do Mercosul. Os primeiros passos estão sendo dados, embora não sejam, até o momento, suficientes para dar conta das expressões de uma região tão particular como a fronteiriça. Diante de tais constatações, a leitura que se faz é que as discussões sobre os direitos sociais e o direito à saúde, na região de fronteira, ainda estão no plano discursivo e formal. As garantias legais (leis, acordos, pactos, normas etc.) já existentes, quanto à saúde, não são suficientes para atender às demandas nas regiões fronteiriças. 
BRASIL. Ministério da Integração Nacional. Proposta de reestruturação do programa de desenvolvimento da faixa de fronteira. Bases de uma política integrada de desenvolvimento regional para a faixa de fronteira. Brasília: Ministério da Integração Nacional, Secretaria de Programas Regionais, 2005.

BRASIL. Ministério da Saúde. Norma Operacional Básica do Sistema Único de Saúde - SUS, de 06 de novembro de 1996. Brasília, DF: Ministério da Saúde, 1997.

\section{Norma Operacional de Assistência} à Saúde - SUS, Portaria 373 de27 de fevereiro de 2002. Disponível em: <http://bvsms.saude.gov.br/bvs/saudelegis/gm/2002/ prt0373_27_02_2002.html>. Acesso em: 29 de maio 2012.

BRASIL. Presidência da República. Casa Civil. Lei n. 8080, de 19 de setembro de 1990. Dispõe sobre as condições para a promoção, proteção e recuperação da saúde, a organização e o funcionamento dos serviços correspondentes e dá outras providências. Diário Oficial da União, Brasília, DF, 20 set. 1990.
CHAUÍ, Marilena. Cultura e Democracia: o discurso competente e outras falas. 11. ed. São Paulo: Cortez, 2006. p. 15-25.

FREY, Klaus. Políticas Públicas: um debate conceitual e reflexões referentes à prática da análise de Políticas Públicas no Brasil. Revista de Planejamento e Políticas Públicas, Brasília, n. 21, p. 211-259, jun. de 2000.

GERSCHMAN, Silvia. Municipalização e inovação gerencial: um balanço da década de 1990. Ciênc. saúde coletiva, São Paulo, v. 6, n. 2, p. 417-434, 2001. Disponível em: <http://www.scielo.br/ scielo.php? script=sci_arttext\&pid $=\mathrm{S} 1413812$ $320010002000118 \operatorname{lng}=e n \& n r m=i s o>$. Acesso em: 05 jul. 2013.

GIOVANELLA, Ligia et al. Saúde nas fronteiras: acesso e demandas de estrangeiros e brasileiros não residentes ao SUS nas cidades de fronteira com países do MERCOSUL na perspectiva dos secretários municipais de saúde. Cadernos de Saúde Pública, Rio de Janeiro, v. 23, Sup. 2, p. 251-266, 2007. 
HARTZ, Zulmira Maria de Araújo. Avaliação dos programas de saúde: perspectivas teórico metodológicas e políticas institucionais. Ciênc. saúde coletiva, Rio de Janeiro, v. 4, n. 2, p. 341353, 1999. Disponível em: <http://www.scielo. $\mathrm{br} /$ scielo.php?script=sci_arttext\&pid=S1413-81231999000200009 \&lng $=$ en\& $\mathrm{nrm}=\mathrm{iso}>$. Acesso em: 15 abril 2010.

NOGUEIRA, Vera Maria Ribeiro. Fronteira MERCOSUL: A institucionalidade dos sistemas municipais de saúde e o direito à saúde. Projeto de Pesquisa: CNPq/UFSC/CSE/DSS. Florianópolis, 2006.

NOGUEIRA, Vera Maria Ribeiro; FAGUNDES, Helenara Silveira; PÉREZ, Roser Giménez. Experiências de cooperação entre sistemas e serviços de saúde em linhas de fronteira. CONGRES DE ALASS, 22, 2011, Barcelona. Anais. Barcelona: ALASS, 2011.
NOYA, Javier. Ciudadanos ambivalentes. Actitudes ante la igualdad y el estado de bienestar en España. Madrid: Centro de Investigacones Sociológicas. 2004.

O'DONNELL, Guilhermo. Democracia Delegativa? Revista Novos Estudos, São Paulo, CEBRAP, n.31, p. 25-40, outubro1991.

PREUSS, Lislei Terezinha. 0 direito à saúde na fronteira: duas versões sobre o mesmo tema. Florianópolis: Universidade Federal de Santa Catarina, 2007. (Dissertação (Mestrado em Serviço Social)).

SILVA, Maria Geusina da. 0 local e o global na atenção às necessidades de saúde dos brasiguaios: análise da intervenção profissional do assistente social em Foz do Iguaçu. Florianópolis: Universidade Federal de Santa Catarina, 2006. (Dissertação (Mestrado em Serviço Social). 